\title{
Social Work Students' Perspective on Environmental Justice: Gaps and Challenges for
}

\section{Preparing Students}

In the 1990s, the social work profession concertedly began expanding its definition of environment beyond social and built environments to also include the natural environment in response to Earth's ecological changes (e.g., global warming, pollution disparities, and desertification) (NASW Delegate Assembly, 2003). In recent years, interest in integrating the natural environment into social work teaching, practice, and research has grown in the United States with the creation of the Council on Social Work Education's (CSWE) Committee on Environmental Justice; the Society for Social Work and Research's Changing Urban and Global Environments special interest group; and the American Academy of Social Work and Social Welfare's Create Social Responses to a Changing Environment Grand Challenge (2016). In addition, CSWE's 2015 educational policy and accreditation standards (EPAS) included environmental justice (EJ) ${ }^{1}$ as a core competency (three) and as a component of competency five, policy engagement. There has also been a steady increase in EJ research (Authors, 2018), including an influx in manuscripts conceptualizing how to integrate the natural environment into social work curricula through foundational perspectives such as person-in-environment (e.g., Gray \& Coates, 2015; Philip \& Reisch, 2015; Teixeira \& Krings, 2015).

EJ's growth throughout social work education, research, and practice in the United States is in response to client needs. Nesmith and Smyth's (2015) survey of social work practitioners in a Midwestern state found almost three-quarters of respondents worked with a client experiencing

\footnotetext{
${ }^{1}$ CSWE adopted the United States Environmental Protection Agency's definition of environmental justice from the 1994 EJ executive order, "the fair treatment and meaningful involvement of all people regardless of race, color, national origin, or income with respect to the development, implementation and enforcement of environmental laws, regulations and policies" (2018), For the purpose of this study, we have used the same definition, but recognize that there is a lack of a universally agreed upon definition within the field of social work.
} 
an environmental injustice-when vulnerable populations " bear a disproportionate share of the negative environmental consequences resulting from industrial, governmental and commercial operations or policies', (United States Environmental Protection Agency, 2018). The environmental injustices experienced by social work clients in the United States are diverse and include, but are not limited to, disproportional exposure to and impacts from climate change (e.g., displacement of Alaska Native communities from sea-level rise); natural disasters (e.g., Hurricane Katrina's unbalanced impacts on low-income, black communities); and pollution and environmental toxins (e.g., low-income communities of color experiencing higher rates of asthma, Flint water crisis) (Kemp \& Palinkas, 2015). Specific injustices vary by region, identity (e.g, gender, race), and socioeconomic status (Dominelli, 2013; Drolet \& Simpson, 2017), with low-income communities and persons of color 'hit first and worst' (Faber \& Krieg, 2002).

Despite EJ's relevance, surveyed social work practitioners reported feeling unprepared and powerless to address clients' environmental issues due to a lack of resources, training, and education (Nesmith \& Smyth, 2015). Grise-Owens, Miller, and Owens (2014) hypothesized the lack of appropriate education may be further perpetuated by traditional social work paradigms, which emphasize micro-, mezzo-, and macro-practice and often lack recognition of the interdependencies between social work concerns on a micro scale and global problems. These paradigms may also not be sufficiently complex to engage the meta purview needed to address environmental challenges. Defined as "the global social aspects that both overarch and interact with macro, mezzo, and micro practice,' Grise-Owens et al. (2014, p. 47) argued that a metapractice for social work is necessary due to societal transformations from increasing global interdependence. Without a framework for meta-practice, educators may risk creating a sense of powerlessness, where a problem seems too large to be within one's knowledge scope and skills. 
However, these conclusions remain theoretical, as a paucity of studies exploring why social workers feel unprepared to address environmental challenges exists. As such, this exploratory study aimed to obtain an in-depth and nuanced understanding of the gaps and challenges inhibiting social work practitioners by seeking to better comprehend the lived experiences of sampled social work students who are immersed in social work training and education. Interviewing social work master's-level students also provides insight into any shifts in curriculum or education related to the recent EPAS requirements and broader societal attention to environmental issues since Miller and Hayward's (2014) study noted social work students' increasing interest in learning about and integrating EJ into their post-schooling practice

\section{Methods}

Two researchers conducted semi-structured, phenomological interviews with 14 students from seven MSW programs in the United States from July to December 2016 to understand how social work students experience EJ in their curricula. Sample size was consistent with recommendations for achieving a saturation of themes in qualitative, phenomenological studies (Creswell, 2013). Non-probability, maximum variation sampling was used to obtain a sample that was geographically, racially, and ethnically diverse, and represented private and public, and practice and research-oriented (i.e., absence or presence of a doctoral program) programs. Table 1 displays participant demographics and their MSW program characteristics. Participants were racially diverse with over half $(n=8)$ identifying as a person of color, in comparison to the $50.8 \%$ of MSW students nationally who identify as White (non-Hispanic). Though this sample was largely female (85.7\%), it was consistent with national social work student demographics, which reported $85.3 \%$ of full-time students and $85.1 \%$ of part-time students identifying as female 
in 2017 (CSWE, 2017). Both research-oriented programs and programs in the Rocky Mountain region were overrepresented compared to national statistics (CSWE, 2017).

Recruitment occurred electronically through listservs of various graduate schools of social work, and through program coordinators or social work faculty members who circulated the recruitment email at their respective universities. Students emailed the researchers to indicate interest, and an interview was then scheduled. Participants were emailed a consent form prior to the interview, and the interviewer received verbal consent before conducting the interview. Participant inclusion criteria was the completion of one semester of a MSW program. MSW programs were selected over bachelor programs since the master's degree is considered the profession's terminal degree for practice. Interviews took place over phone and lasted between 25 to 45 minutes. Both interviewers had advanced training in qualitative methods. All participants received a \$15 Amazon e-gift card at the interview's completion. The authors' university-based Institutional Review Board approved the study protocol.

A semi-structured interview guide was used to facilitate interviews. Participant insights and experiences largely directed the interview; however, interviews discussed three main topics: 1) understanding of EJ, 2) EJ's relevance to social work, and 3) barriers to addressing EJ. Example questions included: "'What does environmental justice mean to you?', (topic 1); "Can you describe social work issues included in environmental justice?"' (topic 2); and "Do you feel prepared to address environmental justice in your placement? Why or why not?', (topic 3). Interviews were recorded, transcribed, and analyzed in Dedoose using an inductive, iterative coding process that reduced content to themes and codes through three cycles (Saldaña, 2013). Two researchers independently coded the data using descriptive and process coding (first-cycle), emotion and value coding (second-cycle), and focus and pattern coding (third-cycle) (Saldaña, 
2013). Focus coding used a codebook generated from first and second-cycle codes with inter-rater agreement assessed at $93.8 \%$.

\section{Results}

\section{Relevant, But Unprepared}

Of the 14 student participants, $13(92.8 \%)$ reported EJ being relevant to social work. Though the sampled students overwhelmingly felt that EJ was relevant to social work, only five students $(35.7 \%)$ disclosed feeling prepared in any capacity to address these issues in their practice, and two of these five participants characterized their preparedness as limited. Participant 7 described, "feeling confident in my ability to recognize EJ. But I guess with my lack of experience with it, I don't think I have a hand directly in it to make a difference, singlehandedly." Another participant described only feeling prepared to address the policy aspects of environmental injustices. These were also the only five participants who received EJ content in their MSW program, though three of the five (60\%) reported content only from a singular social policy course, and two of the three students were from the same program. Of those who received EJ content in more than one course, one (participant 5) was completing a dual degree program and received all EJ content through their public health program.

Student willingness to take ownership of their education also highlighted the lack of EJ content in MSW coursework. Per participant 12, classroom discussions about EJ were depicted as being "student-led" and as noted by multiple participants, students were engaging with EJ content through their own initiative by selecting EJ-focused topics for individual and group assignments. Participant 3 stated that if they wanted content on EJ, "I feel like I have to go out on my own and find out." And as detailed by participant 6 , instructors were supportive when 
students selected EJ focused topics, "but there are certain students who I'll share that I did that, and they'll be like oh I would have totally done the same thing if that was an opportunity."

\section{Barriers in Connecting EJ to Social Work and Social work Clients}

Beyond a lack of exposure to EJ content through instructor-facilitated learning (e.g., readings, coursework, internships), sampled students described an inability to connect the environment to social work clients. Three subthemes arose regarding barriers in connecting EJ to social work clients including: 1) being overwhelmed by the environment's abstract nature and magnitude, 2) personal detachment from the environment and environmental injustices, and 3) lack of understanding of dynamic feedback loops between environment and people.

Though having a strong sense of its relevancy, participants simultaneously described EJ as an elusive concept and "abstract thing" (participant 1) with an expansive reach, "I've been thinking on a very, very small scale in terms of community as opposed to a bigger, like environmental seems like such a bigger word than community." As detailed by participant 6 , “the environment is present in every situation even though it's not. It may not necessarily be visible. It's probably operating or connected to that issue in some way, shape, or form." This magnitude and pervasiveness was described as so "broad" that it was overwhelming (participants 7 and 11). Some participants expressed concern this difficulty was also experienced by social work instructors, causing instructors to "exclude" and "overlook" the relationship between other social justice issues and EJ (participant 3). "The professors... may not see like these overarching systemic issues' connections" [to more micro issues] (participant 2). Participant 13 suggested educators "might hesitate bringing that [environmental health] discussion to class because it doesn't seem like it's an instant fix or something that we can do within the next month." Because of this lack of educator-facilitated learning, when attempting to describe environmental 
injustices, students (e.g., participants 1 and 2) often conflated the built, physical, and natural environments or their definition was limited to geographical barriers impeding access to services.

Participants also expressed that their personal disconnect from the environment and environmental injustices was a barrier to understanding EJ and addressing environmental issues in their practice, particularly since participants' perceptions were that many students select a subfield within social work because of a personal connection to the issue. Students articulated that education about EJ was even more imperative because they lack the experiences themselves "to normalize" clients' situations: "It [EJ education] would help me explain and connect to these individuals because I do not have these experiences personally" (participant 1). And indeed, at the conclusion of interviews, when researchers further explained and defined environmental justice to participants, the students further engaged in the discussion by applying the person-inenvironment perspective and ecological model (e.g., participant 3) to environmental injustices.

Though participants confidently described environmentalism, they could not expand upon it to identify links between environment and people. For example, participant 1 explained, "In my mind environmental justice was protecting the Earth itself, not in how it affected people." Similarly, participant 4 described environmental justice as, "making sure people are taking care of the environment and treating it decently and not doing any harm...I honestly wouldn't even have considered race, ethnicity."

\section{Discussion}

Among this sample of master's students, few indicated their MSW education equipped them to address EJ or exposed them to facilitated learning on EJ, which parallels Miller and Hayward's (2014) and Nesmith and Smyth's (2015) findings. Though substantial attention has been drawn to EJ within social work in the United States through the Grand Challenges, EPAS 
changes, and calls to action, these results suggest social work education and training has not fully adapted to incorporate these topics, and that the problem of being unprepared to address environmental injustices is entrenched throughout the profession.

Students had difficulty contextualizing the environment's role in their practice, particularly in clinical settings. This disconnect was driven by the environment's magnitude, detachment from the environment and environmental injustices, and a lack of understanding of feedback loops between the natural environment and people. Ultimately, these themes underscore the continued divide between social work's micro-macro gap. Further, EJ is an intersectional issue compounded by racial, reproductive, and socio-economic inequities. If social workers are unable to apply EJ frameworks to their practice, then they will be unable to critically examine how environmental inequities intersect with other social issues.

While students' attempts to self-educate on EJ issues can be perceived as a strength to begin building an EJ movement within the profession, it is also problematic. Due to the macro, and potentially even meta elements of the environment's interactions with vulnerable populations, mitigating environmental injustices will require a transdisciplinary approach. However, if the profession continues to rely on a small fragment of self-selecting students and practitioners to self-educate, the field is in danger of lacking an expertise readily identifiable by other disciplinary professionals and being excluded by innovative, transdisciplinary teams. Further, without formal and holistic education facilitated by social work educators_-particularly in systems thinking linking micro and mezzo systems to the more abstract environmentstudents and practitioners, and their interventions, risk overlooking negative feedback loops that perpetuate unintended, and often harmful, consequences. 
Students' inability to connect the environment to social work clients has numerous implications for the ongoing and imperative implementation of EPAS competency three. Tools for integrating the natural environment into psychosocial assessments must be taught in foundational clinical social work courses. For example, questions about pollution and environmental toxins for clients experiencing repeat health concerns or questions about flooding and fire risks integrated into the housing components of assessments. Since EJ emphasizes eliminating systemic environmental inequities related to race/ethnicity, gender, and abilities, content is also relevant to foundational multicultural classes and course content using a power, privilege, and oppression lens. Macro focused students (including students in foundational social work with community courses and courses exploring human behavior in the social environment) should also be encouraged to apply new paradigms, theories, and frameworks such as socialecological systems and One Health to their focus areas and to consider how these frameworks can complement and expand upon existing social work perspectives.

Resources are available to aid educators in developing content to integrate EJ into social work curricula. There are social work specific resources developed by the NASW (e.g., Social Work Speaks), CSWE Committee on Environmental Justice, Katherine A. Kendall Institute for International Social Work Education (e.g., their compilation of effective syllabi) and social work scholars (e.g., Beltrán, Hacker, \& Begun, 2016 among others), as well as textbooks (e.g., Dominelli’s [2012] Green Social Work: From Environmental Crisis to Environmental Justice). In addition, other complementary disciplines may serve as knowledge sources for social worksuch as public health, environmental education, and environmental psychology. Since many clinical faculty maintain licensure, integration of EJ concepts into their curriculum and practice should also be offered in professional development activities such as continuing education. 
Master's programs are also continuously undergoing curriculum reviews in preparation for accreditation. Therefore, administrators also have a role in identifying gaps as well as links and connections between EJ and other courses throughout the curriculum to aid educators that may lack the capacity for integration. If administrators or curriculum leads feel underprepared for this task, other faculty from both within and outside a program should be used in consultation. Educators also need to be cognizant of providing students with concrete strategies for addressing environmental injustices to prevent a sense of overwhelming helplessness that leads to inaction. Due to the students' expressed personal detachment from environmental injustices, experiential courses in diverse settings (e.g., urban, rural, domestic, and international) experiencing environmental injustices would be beneficial. These courses may then generate further interest, which could be addressed by internships with environmentally-focused agencies. To truly imbue EJ's transdisciplinary nature to social work students, the capacity for social work students to engage in classes and problem-solving oriented projects with students from other disciplinary backgrounds is essential. It is likely that elective courses outside social work will be needed to fill this gap (Miller \& Hayward, 2014). However, social work faculty should provide support integrating key social work values into course content through facilitated learning. Limitations related to this exploratory study should be noted. Though we targeted a diverse range of universities, this study used a non-probability sampling and included a relatively small number of participants who likely opted to participate due to interest in the topic. It is possible the current study contains results that summarize perspectives of a few students who are the most interested in EJ. While participants often reflected on other social work experiences unrelated to their current program (e.g., their undergraduate experiences if they had earned a BSW), their knowledge remained school-specific. Thus, these results are not generalizable to 
social work students at large, but rather provide preliminary emergent themes that can inform initial classroom responses while also providing a base of understanding for the future investigation that is necessary to refine and tailor classroom approaches. It is also possible students felt a need to present their beliefs in ways they believe the researcher saw as "correct." While interviewers underwent extensive training in ethical research and interviewing, and placed emphasis on establishing rapport, such limitations are nearly impossible to completely eliminate.

\section{Conclusion}

As Earth's ecological changes continue and increase in severity and frequency, so too will the disproportionate environmental impacts on social work clients. Meanwhile, social work students and practitioners in the United States continue to report a sense of unpreparedness when faced with clients experiencing environmental injustices. This study found that few and inconsistent opportunities for facilitated learning on EJ in social work training and education exist. Additionally, a key to effective training on EJ may be to connect social work approaches to the grandiose nature of these environmental problems, which interact with other social justice issues across micro, mezzo, and macro scales. As the CSWE has mandated the integration of EJ into social work curricula, there may be a need for a paradigm shift within the profession that incorporates a meta-practice, as first postulated by Grise-Owens et al., (2014), into existing approaches to identify the interconnections between social issues long considered under social work's expertise and emerging threats to equitable and sustainable development.

\section{References}

Authors. (2018). Reference removed for blind review. American Academy of Social Work \& Social Welfare (AASWSW) (2016). 'Grand Challenges for Social Work'. Available online at: http://grandchallengesforsocialwork.org 
Beltrán, R., Hacker, A., \& Begun, S. (2016). Environmental justice is a social justice issue: Incorporating environmental justice into social work practice curricula. Journal of Social Work Education, 52(4), 493-502.

Council on Social Work Education (CSWE) Commission, \& CSWE Commission on Accreditation. (2015). 2015 educational policy and accreditation standards for baccalaureate and master's social work programs. Alexandria, VA: CSWE.

CSWE. (2017). Annual statistics on social work education in the United States 2017. Alexandria, VA: CSWE.

Creswell, J. W. (2013). Qualitative inquiry \& research design: Choosing among five approaches ( $3^{\text {rd }}$ ed.). Thousand Oaks, CA: SAGE Publications.

Dominelli, L. (2013). Mind the gap: Built infrastructures, sustainable caring relations, and resilient communities in extreme weather events. Australian Social Work, 66(2), 204-217.

Drolet, J. L., \& Sampson, T. (2014). Addressing climate change from a social development approach: Small cities and rural communities' adaptation and response to climate change in British Columbia, Canada. International Social Work, 60(1), 61-73.

Faber, D. R., \& Krieg, E. J. (2002). Unequal exposure to ecological hazards: Environmental injustices in the Commonwealth of Massachusetts. Environmental Health Perspectives, $110($ supp2), 277-288.

Gray, M., \& Coates, J. (2015). Changing gears: Shifting to an environmental perspective in social work education. Social Work Education, 34(5), 502-512.

Grise-Owens, E., Miller, J., \& Owens, L. (2014). Responding to global shifts: Meta-practice as a relevant social work paradigm. Journal of Teaching in Social Work, 34(1), 46-59.

Kemp, S. P., \& Palinkas, L. A. (2015). Strengthening the Social Response to the Human Impacts 
of Environmental Change. Grand Challenges for Social Work Initiative Working Paper No. 5. American Academy of Social Work and Social Welfare.

Miller, S. E., \& Hayward, R. A. (2014). Social work education's role in addressing people and a planet at risk. Social Work Education, 33(3), 280-295.

NASW Delegate Assembly. (2003). Environmental policy. In Social work speaks: NASW policy statements (6 $6^{\text {th }}$ ed.) (pp. 116-123). Silver Spring, MD: NASW.

Nesmith, A., \& Smyth, N. (2015). Environmental justice and social work education: Social workers' professional perspectives. Social Work Education, 34(5), 484-501.

Philip, D., \& Resich, M. (2015). Rethinking social work’s interpretation of ‘environmental justice': From local to global. Social Work Education, 34(5), 471-483.

Saldaña, J. (2013). The coding manual for qualitative researchers ( $\left.2^{\text {nd }} \mathrm{Ed}.\right)$. Thousand Oaks, CA: Sage Publications.

Teixeira, S., \& Krings, A. (2015). Sustainable social work: An environmental justice framework for social work education. Social Work Education, 34(5), 513-527.

United States Environmental Protection Agency (2018, November 17). Learn about environmental justice. Retrieved from https://www.epa.gov/environmentaljustice/

\section{Tables}

Table 1

Participant Demographics and MSW Program Characteristics, $N=14$

\begin{tabular}{lc}
\hline Characteristic & $\%(n) / M$ \\
\hline Race & \\
White/Caucasian & $42.9 \%(6)$ \\
Black & $14.3 \%(2)$
\end{tabular}


Latina

Native American or

Arab

Asian-Indian

Gender

Female

Male

Transgender
$14.3 \%(2)$

$14.3 \%$ (2)

$7.1 \%$ (1)

$7.1 \%(1)$

\section{MSW Program Characteristics}

\begin{tabular}{lc}
\hline Type & $42.9 \%(6)$ \\
Private & $57.1 \%(8)$ \\
Public & $42.9 \%(6)$ \\
Research versus Practice oriented & \\
Research-oriented & $64.3 \%(9)$ \\
Practice-oriented & $35.7 \%(5)$ \\
Region & \\
Northeast & $14.3 \%(2)$ \\
Mid-Atlantic & $21.4 \%(3)$ \\
Midwest & $14.3 \%(2)$ \\
West & $14.3 \%(2)$ \\
Rocky Mountain & $35.7 \%(5)$ \\
\hline
\end{tabular}

$85.7 \%$ (12)

$7.1 \%$ (1)

$7.1 \%$ (1) 